\title{
Carborane-Based Carbonic Anhydrase Inhibitors: Insight into CAII/CAIX Specificity from a High-Resolution Crystal Structure, Modeling, and Quantum Chemical Calculations
}

\author{
Pavel Mader, ${ }^{1,2}$ Adam Pecina, ${ }^{3}$ Petr Cígler, ${ }^{3}$ Martin Lepšík, ${ }^{3}$ Václav Šícha, ${ }^{4}$ Pavel Hobza, ${ }^{3,5}$ \\ Bohumír Grüner, ${ }^{4}$ Jindřich Fanfrlík, ${ }^{3}$ Jiří Brynda, ${ }^{1,3}$ and Pavlína Řezáčová ${ }^{1,3}$ \\ ${ }^{1}$ Institute of Molecular Genetics, Academy of Sciences of the Czech Republic, Vídeňská 1083, 14000 Prague 4, Czech Republic \\ ${ }^{2}$ Structural Genomics Consortium, University of Toronto, Toronto, ON, Canada M5G 1L7 \\ ${ }^{3}$ Institute of Organic Chemistry and Biochemistry, Academy of Sciences of the Czech Republic, Gilead Sciences and \\ IOCB Research Center, Flemingovo nam. 2, 16610 Prague 6, Czech Republic \\ ${ }^{4}$ Institute of Inorganic Chemistry, Academy of Sciences of the Czech Republic, v.v.i., Hlavni 1001, \\ 25068 Řež near Prague, Czech Republic \\ ${ }^{5}$ Regional Center of Advanced Technologies and Materials, Department of Physical Chemistry, Palacký University, \\ 77146 Olomouc, Czech Republic
}

Correspondence should be addressed to Jindřich Fanfrlík; fanfrlik@uochb.cas.cz, Jiř́i Brynda; brynda@img.cas.cz, and Pavlína Řezáčová; rezacova@uochb.cas.cz

Received 24 April 2014; Accepted 8 June 2014; Published 18 September 2014

Academic Editor: Mariya Al-Rashida

Copyright ( 2014 Pavel Mader et al. This is an open access article distributed under the Creative Commons Attribution License, which permits unrestricted use, distribution, and reproduction in any medium, provided the original work is properly cited.

Carborane-based compounds are promising lead structures for development of inhibitors of carbonic anhydrases (CAs). Here, we report structural and computational analysis applicable to structure-based design of carborane compounds with selectivity toward the cancer-specific CAIX isoenzyme. We determined the crystal structure of CAII in complex with 1-methylenesulfamide1,2-dicarba-closo-dodecaborane at $1.0 \AA$ resolution and used this structure to model the 1-methylenesulfamide-1,2-dicarba-closododecaborane interactions with CAIX. A virtual glycine scan revealed the contributions of individual residues to the energy of binding of 1-methylenesulfamide-1,2-dicarba-closo-dodecaborane to CAII and CAIX, respectively.

\section{Introduction}

Carbonic anhydrases (CAs) play important roles in many physiological and pathophysiological processes. For example, extracellular CAs participate in tumor growth and progression [1]. CAIX, which is selectively expressed in a range of hypoxic tumors, is a validated diagnostic and therapeutic target (recently reviewed in [2-4]). There are 15 human CA isoenzymes, and due to the ubiquity of these enzymes in human tissues, selective inhibition is a very important aspect of drug design.

Three main classes of CA inhibitors have been described to date (reviewed in [5]): (i) metal ion binders (sulfonamides, sulfamides, sulfamates, dithiocarbamates, thiols, and hydroxamates); (ii) compounds that anchor the zinc-coordinated water molecule/hydroxide ion (phenols, carboxylates, polyamines, esters, and sulfocoumarins); and (iii) coumarins and related compounds that bind further away from the metal ion.

CA inhibitors from the first class (metal ion binders) contain specific functional groups that interact with the catalytic $\mathrm{Zn}^{2+}$ ion in the CA active site. These metal-binding functionalities are typically joined to a "ring" structure. This moiety is not necessarily aromatic; however, it is usually consisting of a 5- or 6-membered hydrocarbon ring or conjugated ring system containing nitrogen, oxygen, and/or sulfur. Numerous functional groups have been added to the ring structure scaffold to modify inhibitor properties such as specificity toward a particular CA isoenzyme, $\mathrm{pK}_{\mathrm{a}}$, or solubility (reviewed in [6]). Recently, we reported design of CA inhibitors containing 
space-filling carborane clusters in place of the typical ring structure [7]. We showed that various carborane clusters act as CA inhibitors and that modifying these clusters with an appropriately attached sulfamide group and other substituents leads to compounds with selectivity toward the cancer-specific CAIX isoenzyme.

Boron is one of few chemical elements that can form binary hydrides composed of more than two atoms, which leads to formation of boron cluster compounds (boron hydrides or boranes). Their basic structural feature is formation of a polyhedron with triangular facets held together by 3 center 2-electron bonds with an extensive electron delocalization [8]. A typical structural archetype is represented by the divalent closo- $\mathrm{B}_{12} \mathrm{H}_{12}{ }^{2-}$ anion, an extremely stable compound with a symmetrical 12-vertex icosahedron structure [9]. Replacement of one or more $\left\{\mathrm{BH}^{-}\right\}$in borane cage with $\{\mathrm{CH}\}$ leads to series of carboranes and removal of $\mathrm{BH}$ vertices leads to various open-cage (nido-) species. Carboranes thus offer a large variety of structural archetypes that provide interesting counterparts to organic compounds [10].

Many features of icosahedral 12-vertex carboranes are useful in the design of biologically active compounds. Carboranes have high thermal and chemical stability; therefore, they generally do not undergo catabolism and are nontoxic to the host organism $[11,12]$. The basic closo- $\mathrm{C}_{2} \mathrm{~B}_{10} \mathrm{H}_{12}$ carborane cluster is highly hydrophobic [13]; however, its controlled deboronation can generate water soluble 11-vertex nido- $\mathrm{C}_{2} \mathrm{~B}_{9} \mathrm{H}_{12}{ }^{-}$. These anions represent important intermediates in the synthesis of a family of mainly anionic metal bis(dicarbollides) accessible via metal insertion. Incorporation of carborane cages into the structures of certain substances of medicinal interest can enhance hydrophobic interactions between the boron cluster-coupled pharmaceuticals and their protein targets, increase in vivo stability, and facilitate uptake through cellular membranes $[14,15]$. The successful use of boron clusters as hydrophobic pharmacophores has recently been increasing $[16,17]$. Examples of carborane pharmacophores include boron-containing antifolates [18], HIV protease inhibitors $[19,20]$, and estrogen receptor agonists and antagonists [21], among others [16, 22, 23].

Drug design efforts benefit greatly from knowledge of the $3 \mathrm{D}$ structures of protein-ligand complexes. X-ray crystallography has contributed considerably to the development of CA inhibitors; more than 500 structures of human CA isoenzymes (wild-type and mutant forms) in complex with various inhibitors have offered unprecedented insight into inhibitor binding modes (reviewed in [24]). Structural information coupled with experimental inhibition data can be used to validate various computational approaches to assess inhibitor binding strength. Once a particular theoretical approach reproduces the known data well, it can be used for prospective design. For studies involving metal ions and unusual compounds such as boranes, the use of quantum chemistry (QM) is warranted $[25,26]$. Indeed, we recently used a quantum mechanics/molecular mechanics (QM/MM) methodology to quantitatively describe the binding of two carboranebased sulfamides to CAII [7] and to explain fundamental differences in the binding modes of closo- and nido-cages [27].
Here, we report the X-ray structure of CAII with bound 1methylenesulfamide-1,2-dicarba-closo-dodecaborane (compound 1, Figure 1(a)) determined at $1.0 \AA$ resolution. This atomic-level resolution allowed us to assess in detail the positions of carbon and boron atoms in the carborane cage of $\mathbf{1}$. Additionally, we modeled the complex of 1 with CAIX. We employed a virtual glycine scan to analyze the differences between the interactions of 1 with CAII and CAIX.

\section{Materials and Methods}

2.1. Protein Crystallization and Diffraction Data Collection. For crystallization of human CAII (Sigma, catalogue number C6165) in complex with 1-methylenesulfamide-1,2-dicarbacloso-dodecaborane (compound 1), we adapted a previously described procedure [28]. CAII (at a concentration of $4 \mathrm{mg} \cdot \mathrm{mL}^{-1}$, dissolved in water) was incubated in aqueous solution containing a 2 -fold molar excess of $p$-hydroxymercuribenzoate (Sigma, catalogue number 55540). The protein was concentrated to $10 \mathrm{mg} \cdot \mathrm{mL}^{-1}$ and unbound $p$-hydroxymercuribenzoate was removed with Amicon Ultra-4 concentrators (Merck-Millipore MWCO $10 \mathrm{kDa}$ ).

The complex of CAII with 1 was prepared by adding a 1.1fold molar excess of $\mathbf{1}$ (in DMSO) to the $10 \mathrm{mg} \cdot \mathrm{mL}^{-1}$ solution of CAII in water without $\mathrm{pH}$ adjustment (the final DMSO concentration did not exceed $5 \% \mathrm{v} / \mathrm{v}$ ).

The best diffracting crystals were obtained using the hanging-drop vapor diffusion method under the following conditions: $2 \mu \mathrm{L}$ protein-inhibitor complex solution was mixed with $2 \mu \mathrm{L}$ precipitant solution [2.5 $\mathrm{M}\left(\mathrm{NH}_{4}\right)_{2} \mathrm{SO}_{4}$, $0.3 \mathrm{M} \mathrm{NaCl}$, and $100 \mathrm{mM}$ Tris- $\mathrm{HCl}, \mathrm{pH}$ 8.2] and equilibrated over a reservoir containing $1 \mathrm{~mL}$ of precipitant solution at $18^{\circ} \mathrm{C}$. Crystals with dimensions of $0.3 \mathrm{~mm} \times 0.1 \mathrm{~mm} \times 0.1 \mathrm{~mm}$ grew within 7 days.

For cryoprotection, the crystals were incubated in mother liquor supplemented with $25 \%$ glycerol for approximately $30 \mathrm{~s}$, flash-frozen, and stored in liquid nitrogen. Diffraction data for the CAII complex were collected at $100 \mathrm{~K}$ at the X14.2 BESSY beamline in Berlin, Germany [29]. Data were collected in two passes: the high-resolution range (11.75$1.00 \AA$ ) and the low-resolution range (21.08-1.20 $\AA$ ). The two datasets were integrated with iMOSFLM [30] and merged and scaled with SCALA [31]. Data collection and refinement statistics are summarized in Table 1.

2.2. Structure Determination, Refinement, and Analysis. Crystal structures were solved by difference Fourier method using the CAII structure (PDB code 3IGP [34]) as a starting model. The model was refined using REFMAC5 [35], part of the CCP4 program suite [36]. The model was initially refined with isotropic atomic displacement parameters (ADPs); hydrogen atoms in riding positions were added later. For the final rounds of refinement, we used a mixed isotropicanisotropic model of ADPs: anisotropic ADPs were used for all atoms, and only atoms in alternative conformations were refined isotropically. Atomic coordinates for the structure of 1 were generated by quantum mechanics computation with DFT-D methodology [37] using the B-LYP functional and SVP basis set [38] in the Turbomole program [39]. 


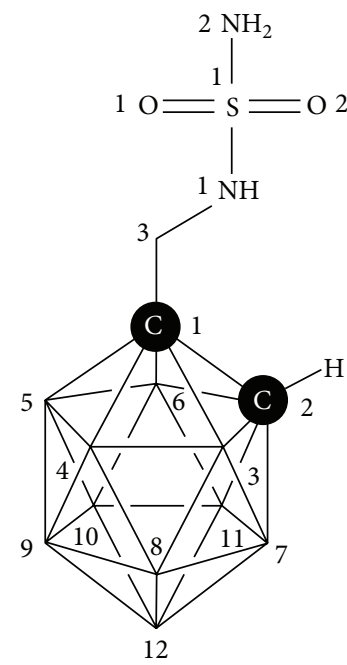

(a)

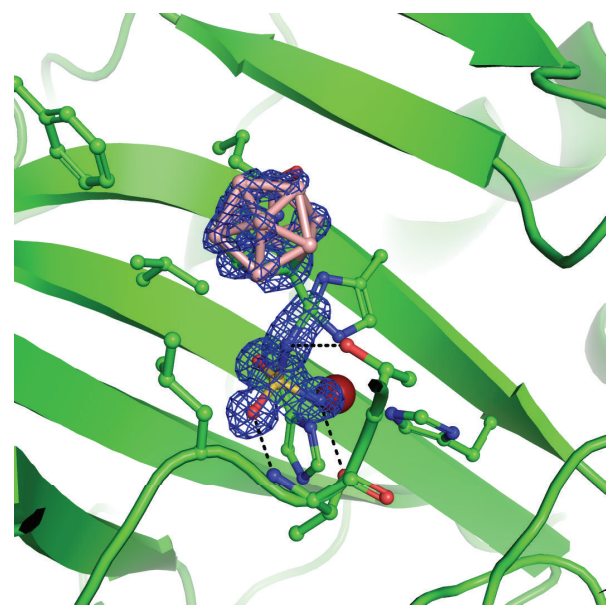

(b)

FIgURE 1: (a) Structural formula of $\mathbf{1}$ with atom numbers used in the crystal structure coordinate file. The vertices in carborane cluster represent BH groups. (b) Crystal structure of CAII in complex with 1. The CAII active site is shown in cartoon representation; residues involved in interactions with the $\mathrm{Zn}^{2+}$ ion (purple sphere) and $\mathbf{1}$ are shown in stick representation with carbon atoms colored green. Boron atoms are colored pink, and other heteroatoms are colored according to standard color coding: oxygen, red; nitrogen, blue; sulfur, yellow. The $2 F o-F c$ electron density map for 1 is contoured at $1 \sigma$.

A geometric library for 1 was generated using the Libcheck program from the CCP4 suite. Coot [40] was used for rebuilding. The quality of the refined model was assessed using MolProbity [33]. The coordinates and structure factors were deposited in the PDB under accession code 4Q78. Final refinement statistics are summarized in Table 1 . All structural figures were prepared using PyMOL 1.4.1 [41].

2.3. Model of CAIX-1 Complex. The complex of CAIX and 1 was modeled by aligning the existing crystal structures of the CAIX catalytic domain (PDB code 3IAI [42]) with the CAII1 complex (PDB code 4MDG [7]) using PyMOL version 1.2 [43]. Preparation of structure coordinate files for further calculations was performed as described before for CAII [27].

The complex was fully optimized using a QM/MM procedure. We used ONIOM-like subtractive scheme [44] with link atoms and mechanical embedding to be consistent with our previous studies [27, 45-48]. The QM part is described at the DFT-D TPSS/TZVP//BLYP/SVP level of theory [39] and comprises 218 atoms including the atoms present in 1 and 8 amino acids (Trp5, Asn62, His64, Gln67, Gln92, Val131, Leu135, and Pro202). The MM part constituted the remainder of the protein, and the surrounding solvent was approximated by a generalized Born (GB) implicit model. Detailed description of the procedure was published in [27]. One crystal water molecule (Wat272) bridging the inhibitors and CAII residues Thr199, Glu106, and Tyr7 was retained to maintain the integrity of the active site. Other water molecules present in the crystal structures were omitted.

The positions of the added hydrogen atoms, $\mathbf{1}$, and 15 amino acids surrounding the ligand (Trp5, Asn62, Gly63, His64, Gln67, Leu91, Gln92, Leu123, Val131, Leu135, Leu141, Thr200, Pro201, Pro202, and Ala204) were relaxed in a GB implicit solvent model using the FIRE algorithm followed by $10 \mathrm{ps}$ annealing from $100 \mathrm{~K}$ or $150 \mathrm{~K}$ to $0 \mathrm{~K}$ using the Berendsen thermostat [49] in the SANDER module of the AMBER 10 package [50].

2.4. Virtual Glycine Scan. The contribution of the active site amino acids to inhibitor binding was examined by virtual glycine scanning. Individual amino acids in contact with $\mathbf{1}$ in the CAIX-1 model and CAII-1 crystal structure were substituted with glycine. The energy contributions $\left(\Delta \Delta \mathrm{G}_{\text {int }}^{\prime}\right)$ were calculated as the difference between the original $\Delta G_{\text {int }}^{\prime}$ at the QM/MM level with the wild-type amino acid and the new $\Delta G_{\text {int }}^{\prime}$ with the mutated glycine residue [27].

\section{Results and Discussion}

3.1. Crystal Structure of CAII in Complex with 1 at Atomic Resolution. The overall structure of CAII in complex with $\mathbf{1}$ was refined to $1.0 \AA$ resolution. This high resolution allowed us to observe details that could not be fully resolved in the complex structure determined previously at lower resolution. Atomic resolution was achieved by derivatization of CAII using the 4-(hydroxymercury)benzoic acid (abbreviated MBO in the cif library of small molecules) method described by [28]. The mercury atom of $\mathrm{MBO}$ covalently binds to $S \gamma$ of Cys206. This modification allows formation of a hydrogen bond between the OZ1 oxygen of the MBO carboxyl group and the mainchain amino group of Tyr40 in the neighboring protein molecule, reinforcing the crystal lattice and increasing the diffraction quality of the crystal. In our structure, MBO is modeled in two alternative conformations with occupancies of 0.6 and 0.2 .

When our atomic resolution structure is compared with the structure of the CAII-1 complex determined at $1.35 \AA$ resolution (PDB code 4MDG [7]), the RMSD value for 
TABLE 1: Data collection and refinement statistics.

\begin{tabular}{|c|c|}
\hline \multicolumn{2}{|l|}{ Data collection statistics } \\
\hline Space group & $P 2_{1}$ \\
\hline Cell parameters $\left(\AA ;^{\circ}\right)$ & $\begin{array}{c}42.20,41.73,72.16 \\
90.0,104.4,90.0\end{array}$ \\
\hline Wavelength $(\AA)$ & 0.9184 \\
\hline Resolution $(\AA)$ & $21.08-1.00(1.05-1.00)$ \\
\hline Number of unique reflections & $108,781(15,490)$ \\
\hline Multiplicity & $3.5(2.5)$ \\
\hline Completeness (\%) & $83.1(81.4)$ \\
\hline$R_{\text {merge }}{ }^{\mathrm{a}}$ & $0.056(0.375)$ \\
\hline Average $I / \sigma(I)$ & $10.8(2.3)$ \\
\hline Wilson B $\left(\AA^{2}\right)$ & 6.5 \\
\hline \multicolumn{2}{|l|}{ Refinement statistics } \\
\hline Resolution range $(\AA)$ & $69.90-1.00(1.03-1.00)$ \\
\hline No. of reflections in working set & $97,856(7,831)$ \\
\hline No. of reflections in test set & $5,426(412)$ \\
\hline$R$ value $(\%)^{\mathrm{b}}$ & $17.5(24.4)$ \\
\hline$R_{\text {free }}$ value $(\%)^{\mathrm{c}}$ & $20.0(26.2)$ \\
\hline RMSD bond length $(\AA)$ & 0.011 \\
\hline RMSD angle $\left({ }^{\circ}\right)$ & 1.53 \\
\hline Number of atoms in $\mathrm{AU}$ & 2297 \\
\hline Number of protein atoms in $\mathrm{AU}$ & 2081 \\
\hline Number of water molecules in AU & 176 \\
\hline Mean ADP value protein/inhibitor $\left(\AA^{2}\right)$ & $12.0 / 17.6$ \\
\hline \multicolumn{2}{|l|}{ Ramachandran plot statistics $^{\mathrm{d}}$} \\
\hline Residues in favored regions (\%) & 96.56 \\
\hline Residues in allowed regions (\%) & 3.44 \\
\hline
\end{tabular}

The data in parentheses refer to the highest-resolution shell.

${ }^{\mathrm{a}} R_{\text {merge }}=\sum_{h k l} \sum_{i} I_{i}(h k l)-\langle I(h k l)\rangle \mid / \sum_{h k l} \sum_{i} I_{i}(h k l)$, where $I_{i}(h k l)$ is the individual intensity of the $i$ th observation of reflection $h k l$ and $\langle I(h k l)\rangle$ is the average intensity of reflection $h k l$ with summation over all data.

${ }^{\mathrm{b}} R$ value $=|| F_{o}|-| F_{c}|| /\left|F_{o}\right|$, where $F_{o}$ and $F_{c}$ are the observed and calculated structure factors, respectively.

${ }^{c} R_{\text {free }}$ is equivalent to $R$ value but is calculated for $5 \%$ of reflections chosen at random and omitted from the refinement process [32].

$\mathrm{d}$ as determined by Molprobity [33].

superposition of the $\mathrm{C} \alpha$ atoms of residues $4-261$ is $0.142 \AA$, a value typical for superposition of identical structures [51]. The N-terminal residue His3 is traced differently in the two structures; double conformations of numerous side chains (e.g., Glu14, His64, and Gln74) are resolved in the atomic resolution structure. We found an additional difference in the loop formed by amino acid residues 124-139, with a maximum difference of $0.738 \AA$ for the position of Gln136 $\mathrm{C} \alpha$. Gln136 forms van der Waals contacts with the MBO covalently attached to Cys206. The positions of Phe131 and Val135, which form a hydrophobic rim at the active site, are also influenced by $\mathrm{MBO}$ binding. This results in a subtle positional shift of the inhibitor, with an RMSD of $0.145 \AA$ for superposition of 12 atoms in the carborane cage of 1 bound to CAII and CAII derivatized by MBO. This value is below the value observed for superposition of identical structures [51].

Atomic-level resolution allowed us to resolve the carbon and boron atom positions in the symmetrical carborane

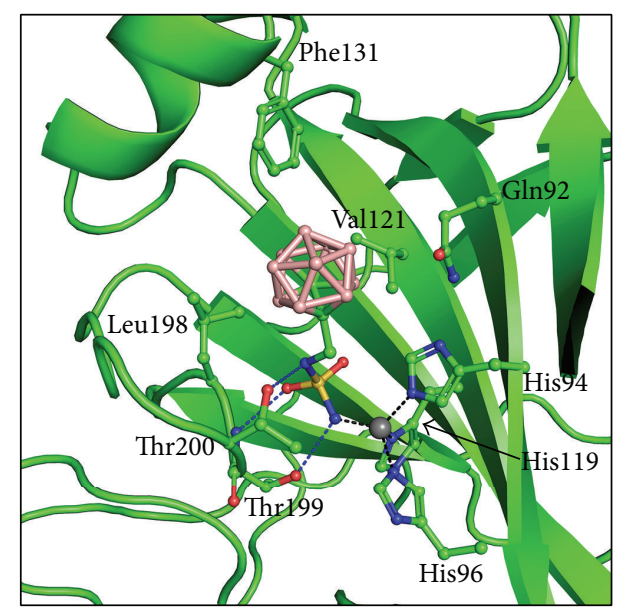

FIgURE 2: Interactions of $\mathbf{1}$ with CAII. The protein is shown in cartoon representation; residues involved in interactions with the $\mathrm{Zn}^{2+}$ ion (gray sphere) and $\mathbf{1}$ are shown in stick representation. Polar interactions are represented by blue dashed lines; $\mathrm{Zn}^{2+}$ ion coordination is shown as black dashed lines.

cage of $\mathbf{1}$. When analyzing the values of the electron density map at positions of atoms bonded to the $\mathrm{Cl}$ atom, we can assume that positions with higher density levels are more likely to be carbon than boron atoms. Similar analysis was done by others for boron-containing inhibitor of human dihydrofolate reductase [18]. The C2 atom of the carborane cage (Figure 1(a)) was modeled into the position with an electron density value of $1.16 \mathrm{e} / \AA^{3}$, which was approximately $0.15 \mathrm{e} / \AA^{3}$ higher than those for the B3, B4, B5, and B6 atoms. To exclude the possibility that higher density is caused by model bias, we altered the composition of the cage by replacing the $\mathrm{C} 2$ atom with a boron atom. Electron density values did not change significantly after several rounds of refinement cycles.

Thus, we can conclude that the most probable position of the second carbon atom in the carborane cage of $\mathbf{1}$ is the position assigned to the $\mathrm{C} 2$ atom in our crystal structure. This is in good agreement with the recently published QM/MM modeling study [27].

3.2. Detailed Analysis of Inhibitor Interactions with CAII. The crystal structure of human CAII in complex with $\mathbf{1}$ determined at $1.0 \AA$ resolution confirmed the key interactions that our group observed previously [7]. The compound fits very well into the CAII active site cavity and makes numerous polar and nonpolar interactions with the residues in the enzyme active site. The sulfamide moiety, which forms key polar interactions with the active site $\mathrm{Zn}^{2+}$ ion, also makes polar interactions with Thr199 typical of other sulfamide inhibitors of CAII (Figure 2). The linker $\mathrm{NH}$ group forms an additional polar interaction with $\mathrm{O} \gamma$ of Thr200. The compound makes several van der Waals interactions with residues Gln92, His94, His96, His119, Val121, Phe131, Leu198, and Thr200 (Figure 2). All interactions between the inhibitor and protein are summarized in Table 2. 


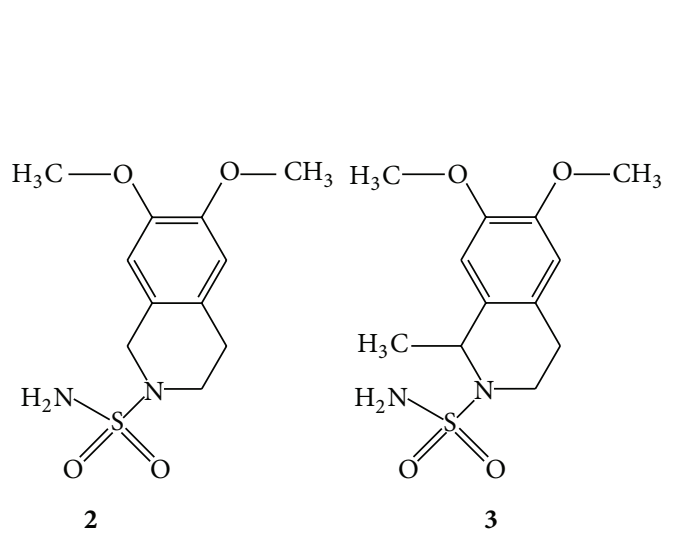

(a)

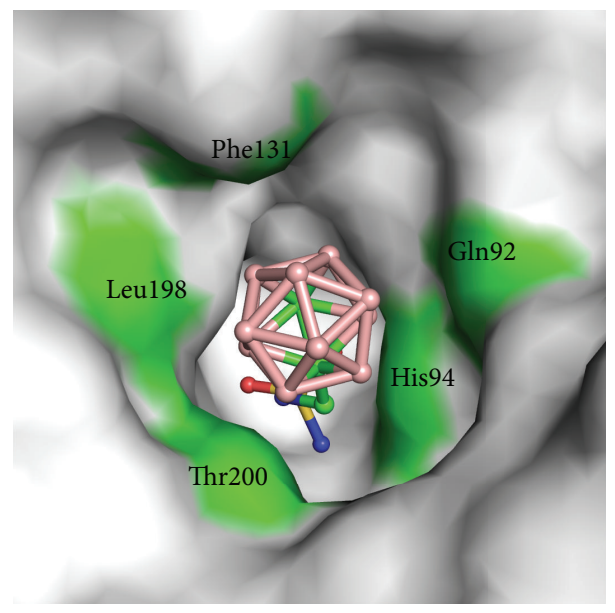

(c)

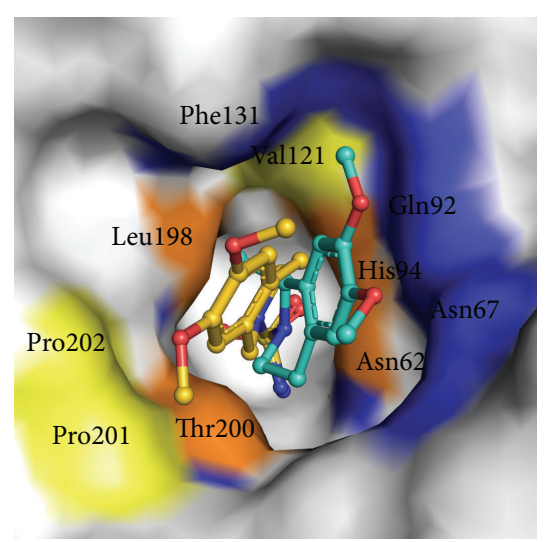

(b)

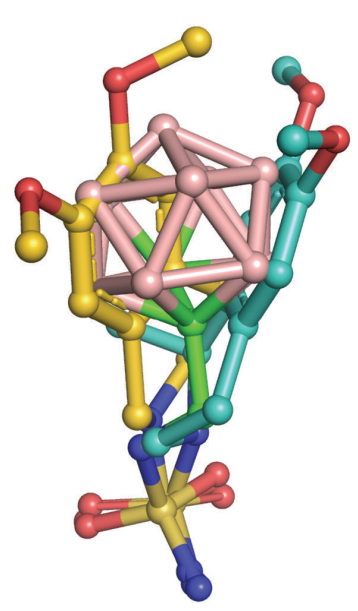

(d)

FIgURE 3: (a) Structural formulas of $\mathbf{2}$ and 3. (b) Interactions of $\mathbf{2}$ and $\mathbf{3}$ with the CAII active site. Compound $\mathbf{2}$ is represented with golden carbon atoms, while the carbon atoms of $\mathbf{3}$ are colored turquoise. Surface of residues making contacts with the isoquinoline moiety of $\mathbf{2}$ and $\mathbf{3}$ are highlighted in yellow and blue, respectively. Surface of residues colored orange make contacts with both compounds. Atoms involved in contacts with the sulfonamide groups are not highlighted. (c) Interactions of 1 with the CAII active site. Surface of residues making contacts with the carborane and linker moiety of $\mathbf{1}$ are highlighted in green. Atoms involved in contacts with the sulfonamide groups are not highlighted. (d) Superposition of binding poses of 1, 2, and 3 in the CAII active site. Superposition of the complex structures was based on the best fit for $\mathrm{C} \alpha$ atoms of CAII residues 6-261.

The idea of designing CA inhibitors containing a carborane cluster moiety originated from our previous structural studies of isoquinoline-containing sulfonamide inhibitors (Figure 3(a)). Structural analysis of CAII in complex with 6,7dimethoxy-1,2,3,4-tetrahydroisoquinolin-2-ylsulfonamide (2, PDB code 3IGP, [34]) and 6,7-dimethoxy-1-methyl-1,2,3,4tetrahydroisoquinolin-2-ylsulfonamide (3, PDB code 3PO6, [52]) revealed two distinct binding modes that engage two opposite sides of the enzyme active site cavity (Figure 3(b)). Following this analysis, we hypothesized that the binding space within the enzyme active site cavity could be effectively filled with a bulky hydrophobic molecule with a spherical structure. This led to design of $\mathbf{1}$ which exhibited inhibitory property to CAII and CAIX with Ki values in submicromolar range. Structural analysis of CAII-1 indicates that our structure-based design was sound. We found that the carborane cluster interacts with both sides of the enzyme active site as predicted (Figure 3(c), Table 3 ) and that the position of $\mathbf{1}$ in the CAII active site superposes well with the two binding modes observed for 2 and 3 (Figure 3(d)).

3.3. Model of the CAIX-1 Complex. The CAII-1 crystal structure was used to model binding of compound 1 into the CAIX active site using QM/MM methods (Figure 4).

The substrate binding sites of CAII and CAIX differ by only six amino acids: Asn67 of CAII is replaced by Gln in CAIX, Ile91 by Leu, Trp123 by Leu, Phel31 by Val, Val135 by Leu, and Leu 204 by Ala. These variations result in a differently shaped active site cavity, which accommodated $\mathbf{1}$ in a slightly different pose (Figure 4). While the position of the sulfamide anchor remained unchanged, the carborane cluster shifted by $2.1 \AA$ (expressed as a difference in the position of B12) away from the central $\beta$-sheet. In CAIX-1, the carborane interacts more with the opposite site of the active site, specifically with amino acid residues His94, His96, Glu106, Leu198, Thr199, Thr200, and Pro201 (Figure 4, Table 3). All polar and van der 
TABLE 2: List of contacts between CAII and $\mathbf{1}$.

\begin{tabular}{|c|c|c|c|c|}
\hline & CAII & & 1 & \\
\hline & & Atom & Atom $^{a}$ & Distance $[\AA]^{\mathrm{b}}$ \\
\hline & $\mathrm{Zn}$ & $\mathrm{ZN}$ & N2 & $1.87^{c}$ \\
\hline & $\mathrm{Zn}$ & $\mathrm{ZN}$ & S & 3.04 \\
\hline & $\mathrm{Zn}$ & $\mathrm{ZN}$ & $\mathrm{O} 2$ & 3.05 \\
\hline 92 & Gln & OE1 & B6 & 3.47 \\
\hline 92 & Gln & OE1 & B11 & 3.52 \\
\hline 92 & Gln & $\mathrm{CD}$ & B6 & 3.84 \\
\hline 94 & His & CE1 & $\mathrm{O} 2$ & 2.97 \\
\hline 94 & His & NE2 & $\mathrm{N} 2$ & 3.23 \\
\hline 94 & His & NE2 & $\mathrm{O} 2$ & 3.31 \\
\hline 94 & His & CE1 & $\mathrm{C} 3$ & 3.67 \\
\hline 94 & His & NE2 & S & 3.81 \\
\hline 94 & His & CE1 & $\mathrm{N} 2$ & 3.82 \\
\hline 94 & His & CE1 & S & 3.84 \\
\hline 94 & His & NE2 & C3 & 3.94 \\
\hline 96 & His & NE2 & $\mathrm{N} 2$ & 3.14 \\
\hline 96 & His & CE1 & $\mathrm{N} 2$ & 3.56 \\
\hline 119 & His & ND1 & N2 & 3.39 \\
\hline 119 & His & ND1 & $\mathrm{O} 2$ & 3.88 \\
\hline 119 & His & $\mathrm{CE} 1$ & $\mathrm{~N} 2$ & 3.96 \\
\hline 121 & Val & CG2 & $\mathrm{O} 2$ & 3.82 \\
\hline 131 & Phe & $\mathrm{CZ}$ & B8 & 3.83 \\
\hline 131 & Phe & $\mathrm{CZ}$ & B7 & 3.97 \\
\hline 198 & Leu & CA & O1 & 3.09 \\
\hline 198 & Leu & $\mathrm{C}$ & O1 & 3.36 \\
\hline 198 & Leu & CB & O1 & 3.60 \\
\hline 198 & Leu & CD2 & $\mathrm{O} 1$ & 3.63 \\
\hline 198 & Leu & CD1 & B3 & 3.86 \\
\hline 199 & Thr & $\mathbf{N}$ & O1 & 2.70 \\
\hline 199 & Thr & OG1 & N2 & 2.74 \\
\hline 199 & Thr & OG1 & O1 & 3.58 \\
\hline 199 & Thr & OG1 & $S$ & 3.78 \\
\hline 199 & Thr & $\mathrm{N}$ & $S$ & 3.83 \\
\hline 199 & Thr & CA & O1 & 3.83 \\
\hline 199 & Thr & $\mathrm{CB}$ & $\mathrm{N} 2$ & 3.98 \\
\hline 200 & Thr & OG1 & N1 & 3.02 \\
\hline 200 & Thr & OG1 & C3 & 3.14 \\
\hline 200 & Thr & OG1 & B4 & 3.36 \\
\hline 200 & Thr & OG1 & B3 & 3.56 \\
\hline 200 & Thr & OG1 & $\mathrm{Cl}$ & 3.66 \\
\hline
\end{tabular}

${ }^{a}$ Atom labels correspond to those shown in Figure 1(a).

${ }^{\mathrm{b}}$ All contacts with a distance between ligand and protein (or $\mathrm{Zn}$ ) atoms less than or equal to $4 \AA$ are listed.

${ }^{\mathrm{c}}$ Polar interactions are highlighted in bold.

Waals interactions between CAIX and $\mathbf{1}$ are summarized in Table 4 .

We used a virtual glycine scan to study the roles of individual amino acid side chains in the active sites of CAII and CAIX in binding of $\mathbf{1}$. The changes in free energy of

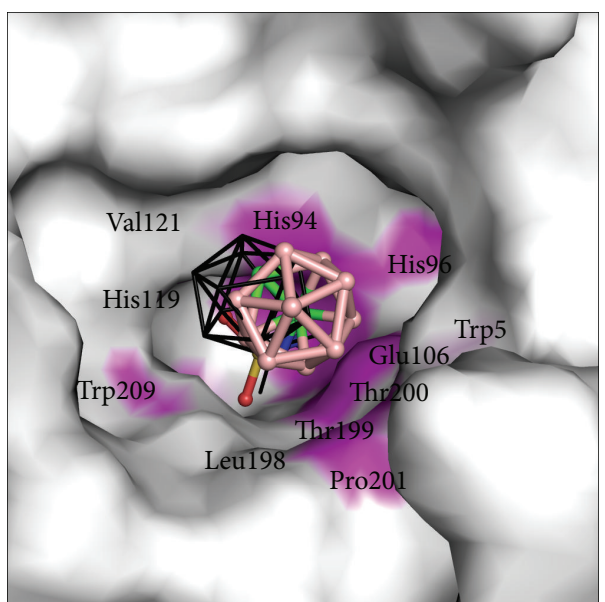

FIgURE 4: Interactions of 1 with the CAIX active site. Atoms making contacts with the carborane and linker moiety of $\mathbf{1}$ are highlighted in magenta. Atoms involved in contacts with the sulfonamide groups are not highlighted. Superposition of the binding pose of $\mathbf{1}$ in CAII is shown as black lines. Superposition is based on the best fit for $\mathrm{C} \alpha$ atoms of all residues of CAII onto CAIX.

TABLE 3: CAII or CAIX residues interacting with $\mathbf{1}, \mathbf{2}$, and 3.

\begin{tabular}{lccc}
\hline & $\begin{array}{c}\text { CAII } \\
\mathbf{1}^{\mathrm{a}}\end{array}$ & $\mathbf{3}^{\mathrm{c}}$ & $\begin{array}{c}\text { CAIX } \\
\mathbf{1}^{\mathrm{d}}\end{array}$ \\
\hline & & & Trp5 \\
& & Asn62 & \\
Gln92 & Gln92 & Gln92 & \\
His94 & His94 & His94 & His94 \\
His96 & His96 & His96 & His96 \\
& & & Glu106 \\
His119 & His119 & His119 & His119 \\
Val121 & & Val121 & Val121 \\
Phe131 & Phe131 & Phe131 & \\
& Val143 & Val143 & \\
Leu198 & Leu198 & Leu198 & Leu198 \\
Thr199 & Thr199 & Thr199 & Thr199 \\
Thr200 & Thr200 & Thr200 & Thr200 \\
& Pro201 & & Pro201 \\
& Pro202 & & Trp209 \\
\hline & Trp209 & &
\end{tabular}

Interacting residues were identified from ${ }^{\mathrm{a}}$ crystal structure $4 \mathrm{Q} 78$ (this work); ${ }^{b}$ crystal structure 3IGP [34]; ${ }^{c}$ crystal structure 3PO6 [52]; ${ }^{d}$ computational model (this work); ${ }^{\mathrm{e}}$ residues making polar interactions are highlighted in bold.

interaction $\left(\Delta \Delta \mathrm{G}_{\text {int }}^{\prime}\right)$ upon mutation of a given amino acid residue to glycine are shown in Figure 5.

The largest energy change $(2.6 \mathrm{kcal} / \mathrm{mol})$ occurred for Trp5, which is positioned closer to 1 in CAIX-1 than in CAII1. The side chain of Trp5 forms several dihydrogen bonds with the carborane cage of 1 . The shortest one has a $\mathrm{H} \cdots \mathrm{H}$ distance of $2.3 \AA$. The other major contributor to strong 
TABLE 4: Interactions between CAIX and $\mathbf{1 .}$

\begin{tabular}{|c|c|c|c|c|}
\hline \multirow{2}{*}{\multicolumn{2}{|c|}{$\begin{array}{c}\text { CAIX } \\
\text { Residue }\end{array}$}} & \multicolumn{3}{|c|}{1} \\
\hline & & Atom & Atom $^{\mathrm{a}}$ & Distance $[\AA]^{\mathrm{b}}$ \\
\hline & $\mathrm{Zn}$ & $\mathrm{ZN}$ & N2 & $2.1^{\mathrm{c}}$ \\
\hline & $\mathrm{Zn}$ & $\mathrm{ZN}$ & S & 3.3 \\
\hline & $\mathrm{Zn}$ & $\mathrm{ZN}$ & $\mathrm{O} 2$ & 3.5 \\
\hline 5 & $\operatorname{Trp}$ & $\mathrm{CZ2}$ & B5 & 3.74 \\
\hline 5 & $\operatorname{Trp}$ & $\mathrm{CZ2}$ & $\mathrm{B} 10$ & 3.81 \\
\hline 94 & $\mathrm{His}$ & CE1 & $\mathrm{O} 2$ & 3.15 \\
\hline 94 & His & CE1 & $\mathrm{C} 3$ & 3.74 \\
\hline 94 & His & NE2 & N2 & 3.36 \\
\hline 94 & His & NE2 & S & 3.88 \\
\hline 94 & $\mathrm{His}$ & NE2 & $\mathrm{O} 2$ & 3.45 \\
\hline 94 & His & NE2 & $\mathrm{C} 3$ & 3.76 \\
\hline 96 & His & CE1 & N2 & 3.99 \\
\hline 96 & His & NE2 & N2 & 3.49 \\
\hline 106 & Glu & OE2 & N2 & 3.71 \\
\hline 119 & His & ND1 & N2 & 3.37 \\
\hline 119 & His & CE1 & N2 & 3.83 \\
\hline 121 & Val & CG2 & $\mathrm{O} 2$ & 3.58 \\
\hline 198 & Leu & $\mathrm{CA}$ & $\mathrm{O} 1$ & 3.04 \\
\hline 198 & Leu & $\mathrm{CB}$ & $\mathrm{O} 1$ & 3.4 \\
\hline 198 & Leu & $\mathrm{CD} 2$ & $\mathrm{O} 1$ & 3.43 \\
\hline 198 & Leu & $\mathrm{C}$ & $\mathrm{O} 1$ & 3.38 \\
\hline 199 & Thr & $\mathrm{N}$ & S & 3.88 \\
\hline 199 & Thr & $\mathbf{N}$ & 01 & 2.79 \\
\hline 199 & Thr & $\mathrm{CA}$ & $\mathrm{O} 1$ & 3.96 \\
\hline 199 & Thr & $\mathrm{CB}$ & N2 & 3.85 \\
\hline 199 & Thr & OG1 & N2 & 2.63 \\
\hline 199 & Thr & OG1 & $S$ & 3.69 \\
\hline 199 & Thr & OG1 & $\mathrm{O} 1$ & 3.65 \\
\hline 200 & Thr & OG1 & $\mathrm{Cl}$ & 3.77 \\
\hline 200 & Thr & OG1 & B5 & 3.56 \\
\hline 200 & Thr & OG1 & N1 & 3.13 \\
\hline 200 & Thr & OG1 & C3 & 3.31 \\
\hline 200 & Thr & OG1 & B4 & 3.64 \\
\hline 201 & Pro & $\mathrm{O}$ & B4 & 3.6 \\
\hline 201 & Pro & $\mathrm{O}$ & B10 & 3.49 \\
\hline 201 & Pro & $\mathrm{O}$ & B8 & 3.96 \\
\hline 209 & $\operatorname{Trp}$ & $\mathrm{CZ2}$ & O1 & 3.74 \\
\hline
\end{tabular}

${ }^{a}$ Atom labels correspond to those shown in Figure 1(a).

${ }^{\mathrm{b}}$ All contacts with a distance less than or equal to $4 \AA$ between ligand and protein (and $\mathrm{Zn}$ ) atoms are listed.

${ }^{c}$ Polar interactions are highlighted in bold.

CAIX-1 binding was Asn62; the energy of binding exceeded that in CAII-1 by nearly $1 \mathrm{kcal} / \mathrm{mol}$. These contributions were cancelled out by differences in binding energy contributions of amino acid residues 131 (Phe/Val) and 135 (Val/Leu), which were lower in CAIX by 0.7 and $0.9 \mathrm{kcal} / \mathrm{mol}$, respectively. The energy changes of other residues were small.

When we compared binding of 1 to CAII and CAIX, we noted that the favorable energy changes in CAIX-1 due to the binding of residues Trp5, Asn62, and His64 were slightly

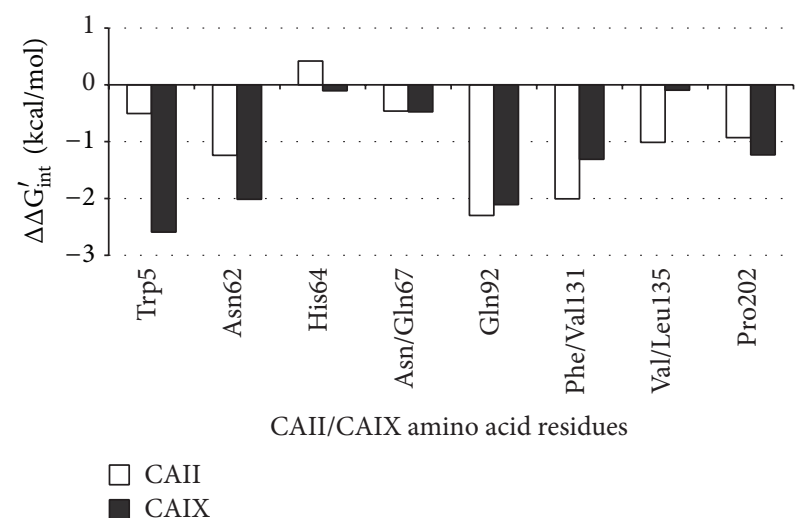

FIGURE 5: Results of virtual glycine scan showing contributions of individual residues to the energy of binding of $\mathbf{1}$ to CAII and CAIX, respectively.

larger than the unfavorable changes in binding caused by the different amino acids at residues 131 and 135 . This is in qualitative agreement with the experimental $K_{i}$ values, which are $700 \pm 141 \mathrm{~nm}$ for inhibition of CAII and $380 \pm 111 \mathrm{nM}$ for inhibition of CAIX [7].

\section{Conclusions}

We determined to atomic resolution the crystal structure of CAII in complex with 1-methylenesulfamide-1,2-dicarbacloso-dodecaborane (1), a parent compound of a recently reported series of CA inhibitors containing carborane cages [7]. Comparing this crystal structure with those of CAII complexes with conventional organic inhibitors showed that the three-dimensional cluster fills the enzyme active site cavity. Atomic-level resolution allowed us to distinguish the positions of carbon and boron atoms in the carborane cage. The crystal structure also served as a model for construction of the CAIX-1 computational model. Virtual glycine scan enabled us to quantify the contributions of individual residues to the energy of binding of $\mathbf{1}$ to CAII and CAIX and uncover differences of the enzyme active site cavities. Structural and computational analysis will be used in future structure-based design of carborane compounds with selectivity toward the cancer-specific CAIX isoenzyme.

\section{Conflict of Interests}

The authors declare that there is no conflict of interests regarding the publication of this paper.

\section{Authors' Contribution}

Pavel Mader and Adam Pecina contributed equally to this work.

\section{Acknowledgments}

This work was supported by the Technology Agency of the Czech Republic (Project TE01020028) and in part by Research Projects RVO 68378050 and 61388963 awarded by 
the Academy of Sciences of the Czech Republic. The authors acknowledge the financial support of the Czech Science Foundation (P208/12/G016) and the operational program Research and Development for Innovations of the European Social Fund (CZ 1.05/2.1.00/03/0058). They also thank Gilead Sciences and IOCB Research Centre for financial support. The use of MX14.2 operated by the Helmholtz-Zentrum Berlin at the BESSY II electron storage ring (Berlin-Adlershof, Germany) to collect diffraction data is acknowledged.

\section{References}

[1] P. Swietach, S. Patiar, C. T. Supuran, A. L. Harris, and R. D. Vaughan-Jones, "The role of carbonic anhydrase 9 in regulating extracellular and intracellular $\mathrm{pH}$ in three-dimensional tumor cell growths," The Journal of Biological Chemistry, vol. 284, no. 30, pp. 20299-20310, 2009.

[2] P. C. McDonald, J. Winum, C. T. Supuran, and S. Dedhar, "Recent developments in targeting carbonic anhydrase IX for cancer therapeutics," Oncotarget, vol. 3, no. 1, pp. 84-97, 2012.

[3] F. E. Lock, P. C. McDonald, Y. Lou et al., "Targeting carbonic anhydrase IX depletes breast cancer stem cells within the hypoxic niche," Oncogene, vol. 32, no. 44, pp. 5210-5219, 2013.

[4] N. K. Tafreshi, M. C. Lloyd, M. M. Bui, R. J. Gillies, and D. L. Morse, "Carbonic anhydrase IX as an imaging and therapeutic target for tumors and metastases," in Carbonic Anhydrase: Mechanism, Regulation, Links to Disease, and Industrial Applications, vol. 75 of Subcellular Biochemistry, pp. 221-254, 2014.

[5] S. M. Monti, C. T. Supuran, and G. de Simone, "Anticancer carbonic anhydrase inhibitors: a patent review (2008-2013)," Expert Opinion on Therapeutic Patents, vol. 23, no. 6, pp. 737749, 2013.

[6] R. McKenna and C. T. Supuran, "Carbonic anhydrase inhibitors drug design,” Subcellular Biochemistry, vol. 75, pp. 291-323, 2014.

[7] J. Brynda, P. Mader, V. Sicha et al., "Carborane-based carbonic anhydrase inhibitors," Angewandte Chemie International Edition in English, vol. 52, pp. 13760-13763, 2013.

[8] W. N. Lipscomb, Boron Hydrides, W.A. Benjamin, New York, NY, USA, 1963.

[9] P. R. Schleyer and K. Najafian, "Stability and three-dimensional aromaticity of closo-monocarbaborane anions, $\mathrm{Cb}_{n-1} \mathrm{H}_{n}{ }^{-}$, and closo-dicarboranes, $\mathrm{C}_{2} \mathrm{~B}_{n-2} \mathrm{H}_{n}$, Inorganic Chemistry, vol. 37, pp. 3454-3470, 1998.

[10] R. E. Williams, in The Borane, Carborane and Carbocation Continuum, J. Casanova, Ed., pp. 3-57, John Wiley \& Sons, New York, NY, USA, 1997.

[11] J. F. Valliant, K. J. Guenther, A. S. King et al., "The medicinal chemistry of carboranes," Coordination Chemistry Reviews, vol. 232, no. 1-2, pp. 173-230, 2002.

[12] Z. J. Lesnikowski, "Boron units as pharmacophores-new applications and opportunities of boron cluster chemistry," Collection of Czechoslovak Chemical Communications, vol. 72, no. 12, pp. 1646-1658, 2007.

[13] J. Plešek, "Potential applications of the boron cluster compounds," Chemical Reviews, vol. 92, no. 2, pp. 269-278, 1992.

[14] J. Seidler, S. L. McGovern, T. N. Doman, and B. K. Shoichet, "Identification and prediction of promiscuous aggregating inhibitors among known drugs," Journal of Medicinal Chemistry, vol. 46, no. 21, pp. 4477-4486, 2003.
[15] M. Sibrian-Vazquez, E. Hao, T. J. Jensen, and M. G. H. Vicente, "Enhanced cellular uptake with a cobaltacarborane-porphyrinHIV-1 Tat 48-60 conjugate," Bioconjugate Chemistry, vol. 17, no. 4, pp. 928-934, 2006.

[16] M. Scholz, M. Steinhagen, J. T. Heiker, A. G. Beck-Sickinger, and E. Hey-Hawkins, "Asborin Inhibits Aldo/Keto Reductase 1A1," ChemMedChem, vol. 6, no. 1, pp. 89-93, 2011.

[17] F. Issa, M. Kassiou, and L. M. Rendina, "Boron in drug discovery: carboranes as unique pharmacophores in biologically active compounds," Chemical Reviews, vol. 111, no. 9, pp. 57015722, 2011.

[18] R. C. Reynolds, S. R. Campbell, R. G. Fairchild et al., "Novel boron-containing, nonclassical antifolates: synthesis and preliminary biological and structural evaluation," Journal of Medicinal Chemistry, vol. 50, no. 14, pp. 3283-3289, 2007.

[19] P. Cigler, M. Kozisek, P. Rezacova et al., "From nonpeptide toward noncarbon protease inhibitors: metallacarboranes as specific and potent inhibitors of HIV protease," Proceedings of the National Academy of Sciences of the United States of America, vol. 102, pp. 15394-15399, 2005.

[20] P. Řezáčová, J. Pokorná, J. Brynda et al., "Design of HIV protease inhibitors based on inorganic polyhedral metallacarboranes," Journal of Medicinal Chemistry, vol. 52, no. 22, pp. 7132-7141, 2009.

[21] Y. Endo, T. Iijima, Y. Yamakoshi et al., "Potent estrogen agonists based on carborane as a hydrophobic skeletal structure: a new medicinal application of boron clusters," Chemistry \& Biology, vol. 8, no. 4, pp. 341-355, 2001.

[22] R. L. Julius, O. K. Farha, J. Chiang, L. J. Perry, and M. F. Hawthorne, "Synthesis and evaluation of transthyretin amyloidosis inhibitors containing carborane pharmacophores," Proceedings of the National Academy of Sciences of the United States of America, vol. 104, no. 12, pp. 4808-4813, 2007.

[23] S. Fujii, H. Masuno, Y. Taoda et al., "Boron cluster-based development of potent nonsecosteroidal vitamin D receptor ligands: direct observation of hydrophobic interaction between protein surface and carborane," Journal of the American Chemical Society, vol. 133, no. 51, pp. 20933-20941, 2011.

[24] V. M. Krishnamurthy, G. K. Kaufman, A. R. Urbach et al., "Carbonic anhydrase as a model for biophysical and physicalorganic studies of proteins and protein-ligand binding," Chemical Reviews, vol. 108, no. 3, pp. 946-1051, 2008.

[25] K. Raha, M. B. Peters, B. Wang et al., "The role of quantum mechanics in structure-based drug design," Drug Discovery Today, vol. 12, no. 17-18, pp. 725-731, 2007.

[26] M. Lepšík, J. Řezáč, M. Kolář, A. Pecina, P. Hobza, and J. Fanfrlík, "The semiempirical quantum mechanical scoring function for in silico drug design," ChemPlusChem, vol. 78, pp. 921-931, 2013.

[27] A. Pecina, M. Lepsik, J. Rezac et al., "QM/MM calculations reveal the different nature of the interaction of two carboranebased sulfamide inhibitors of human carbonic anhydrase II," The Journal of Physical Chemistry B, vol. 117, pp. 16096-16104, 2013.

[28] C. A. Behnke, I. Le Trong, J. W. Godden et al., "Atomic resolution studies of carbonic anhydrase II," Acta Crystallographica D: Biological Crystallography, vol. 66, no. 5, pp. 616-627, 2010.

[29] U. Mueller, N. Darowski, M. R. Fuchs et al., "Facilities for macromolecular crystallography at the Helmholtz-Zentrum Berlin," Journal of Synchrotron Radiation, vol. 19, no. 3, pp. 442449, 2012. 
[30] T. G. G. Battye, L. Kontogiannis, O. Johnson, H. R. Powell, and A. G. Leslie, "iMOSFLM: a new graphical interface for diffraction-image processing with MOSFLM," Acta Crystallographica D, vol. 67, no. 4, pp. 271-281, 2011.

[31] P. Evans, "Scaling and assessment of data quality," Acta Crystallographica Section D: Biological Crystallography, vol. 62, no. 1, pp. 72-82, 2006.

[32] A. T. Brunger, "Free $R$ value: a novel statistical quantity for assessing the accuracy of crystal strucutres," Nature, vol. 355, no. 6359 , pp. $472-475,1992$.

[33] S. C. Lovell, I. W. Davis, W. B. Arendall III et al., "Structure validation by $\mathrm{C} \alpha$ geometry: $\varphi, \psi$ and $\mathrm{C} \beta$ deviation," Proteins, vol. 50, no. 3, pp. 437-450, 2003.

[34] R. Gitto, S. Agnello, S. Ferro et al., "Identification of 3,4-dihydroisoquinoline-2(1H)-sulfonamides as potent carbonic anhydrase inhibitors: synthesis, biological evaluation, and enzymeligand X-ray studies," Journal of Medicinal Chemistry, vol. 53, no. 6, pp. 2401-2408, 2010.

[35] G. N. Murshudov, A. A. Vagin, and E. J. Dodson, "Refinement of macromolecular structures by the maximum-likelihood method," Acta Crystallographica D, vol. 53, no. 3, pp. 240-255, 1997.

[36] "The CCP4 suite: programs for protein crystallography," Acta Crystallographica D, vol. 50, pp. 760-763, 1994.

[37] P. Jurečka, J. Černý, P. Hobza, and D. R. Salahub, "Density functional theory augmented with an empirical dispersion term. Interaction energies and geometries of 80 noncovalent complexes compared with ab initio quantum mechanics calculations," Journal of Computational Chemistry, vol. 28, no. 2, pp. 555-569, 2007.

[38] F. Weigend and R. Ahlrichs, "Balanced basis sets of split valence, triple zeta valence and quadruple zeta valence quality for $\mathrm{H}$ to Rn: design and assessment of accuracy," Physical Chemistry Chemical Physics, vol. 7, no. 18, pp. 3297-3305, 2005.

[39] R. Ahlrichs, M. Bär, M. Häser, H. Horn, and C. Kölmel, "Electronic structure calculations on workstation computers: the program system turbomole," Chemical Physics Letters, vol. 162, no. 3, pp. 165-169, 1989.

[40] P. Emsley and K. Cowtan, "Coot: model-building tools for molecular graphics," Acta Crystallographica D: Biological Crystallography, vol. 60, no. 12, pp. 2126-2132, 2004.

[41] W. L. DeLano, The PyMOL Molecular Graphics System, DeLano Scientific LLC, San Carlos, Calif, USA, 2002, http://www.pymol .org.

[42] V. Alterio, M. Hilvo, A. Di Fiore et al., "Crystal structure of the catalytic domain of the tumor-associated human carbonic anhydrase IX," Proceedings of the National Academy of Sciences of the United States of America, vol. 106, no. 38, pp. 16233-16238, 2009.

[43] W. L. DeLano, The PymoL Molecular Graphics System, DeLano Scientific, Palo Alto, Calif, USA, 2002.

[44] M. Svensson, S. Humbel, R. D. J. Froese, T. Matsubara, S. Sieber, and K. Morokuma, "ONIOM: a multilayered integrated $\mathrm{MO}+\mathrm{MM}$ method for geometry optimizations and single point energy predictions. A test for Diels-Alder reactions and $\mathrm{Pt}\left(\mathrm{P}(t-\mathrm{Bu})_{3}\right)_{2}+\mathrm{H}_{2}$ oxidative addition," The Journal of Physical Chemistry, vol. 100, no. 50, pp. 19357-19363, 1996.

[45] A. Pecina, O. Přenosil, J. Fanfrlík et al., "On the reliability of the corrected semiempirical quantum chemical method (PM6-DH2) for assigning the protonation states in HIV-1 protease/inhibitor complexes," Collection of Czechoslovak Chemical Communications, vol. 76, no. 5, pp. 457-479, 2011.
[46] P. S. Brahmkshatriya, P. Dobeš, J. Fanfrlík et al., "Quantum mechanical scoring: structural and energetic insights into cyclin-dependent kinase 2 inhibition by pyrazolo[1,5-a]pyrimidines," Current Computer-Aided Drug Design, vol. 9, no. 1, pp. 118-129, 2013.

[47] J. Fanfrlík, M. Kolář, M. Kamlar et al., "Modulation of aldose reductase inhibition by halogen bond tuning," ACS Chemical Biology, vol. 8, pp. 2484-2492, 2013.

[48] J. Fanfrlík, P. S. Brahmkshatriya, J. Řezáč et al., "Quantum mechanics-based scoring rationalizes the irreversible inactivation of parasitic Schistosoma mansoni cysteine peptidase by vinyl sulfone inhibitors," Journal of Physical Chemistry B, vol. 117, pp. 14973-14982, 2013.

[49] H. J. C. Berendsen, J. P. M. Postma, W. F. Van Gunsteren, A. Dinola, and J. R. Haak, "Molecular dynamics with coupling to an external bath," The Journal of Chemical Physics, vol. 81, no. 8, pp. 3684-3690, 1984.

[50] D. A. Case, T. E. Cheatham III, T. Darden et al., "The Amber biomolecular simulation programs," Journal of Computational Chemistry, vol. 26, no. 16, pp. 1668-1688, 2005.

[51] M. J. Betts and M. J. E. Sternberg, "An analysis of conformational changes on protein-protein association: implications for predictive docking," Protein Engineering, vol. 12, no. 4, pp. 271283, 1999.

[52] P. Mader, J. Brynda, R. Gitto et al., "Structural Basis for the Interaction between Carbonic Anhydrase and 1,2,3,4-tetrahydroisoquinolin-2-ylsulfonamides," Journal of Medicinal Chemistry, vol. 54, no. 7, pp. 2522-2526, 2011. 

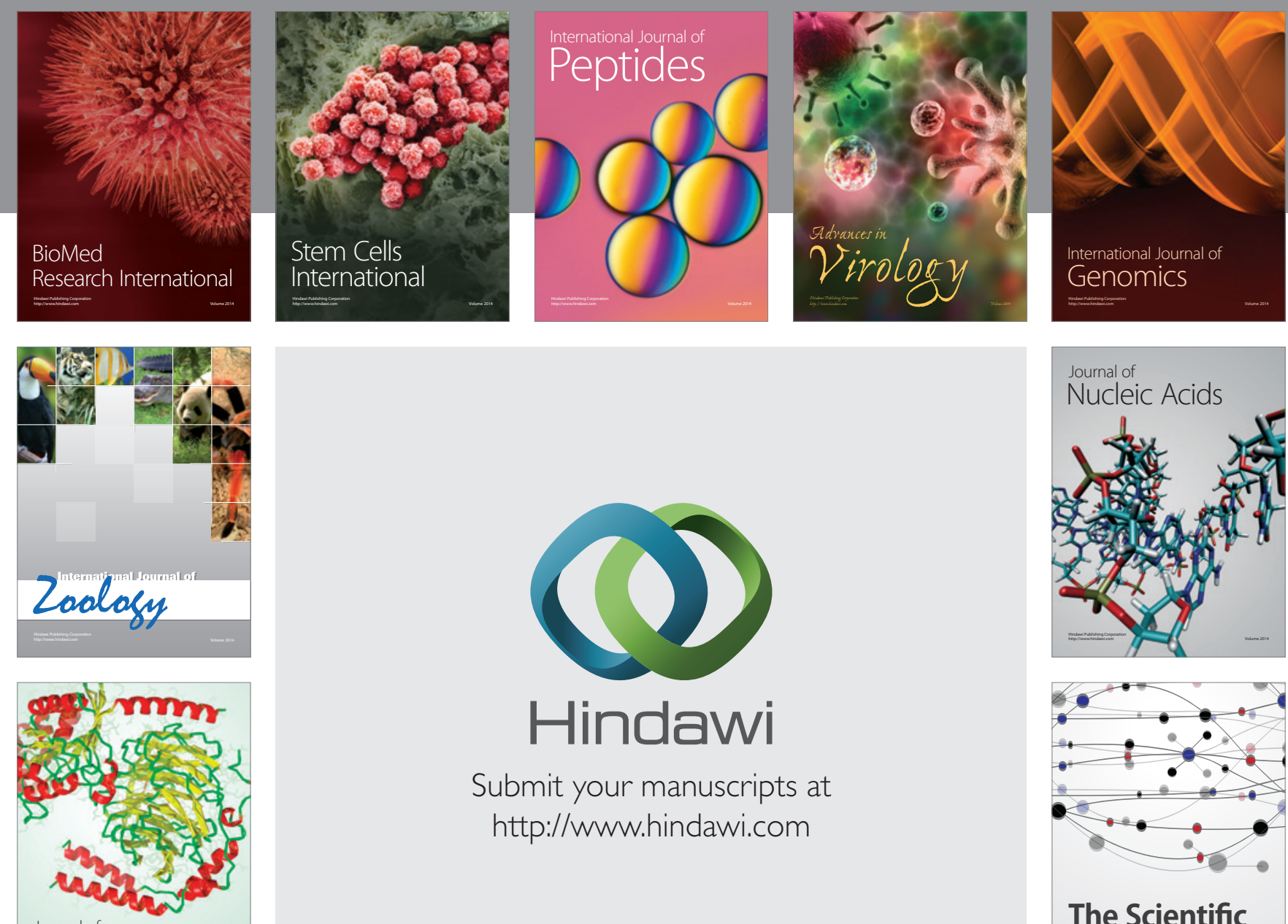

Submit your manuscripts at

http://www.hindawi.com

Journal of
Signal Transduction
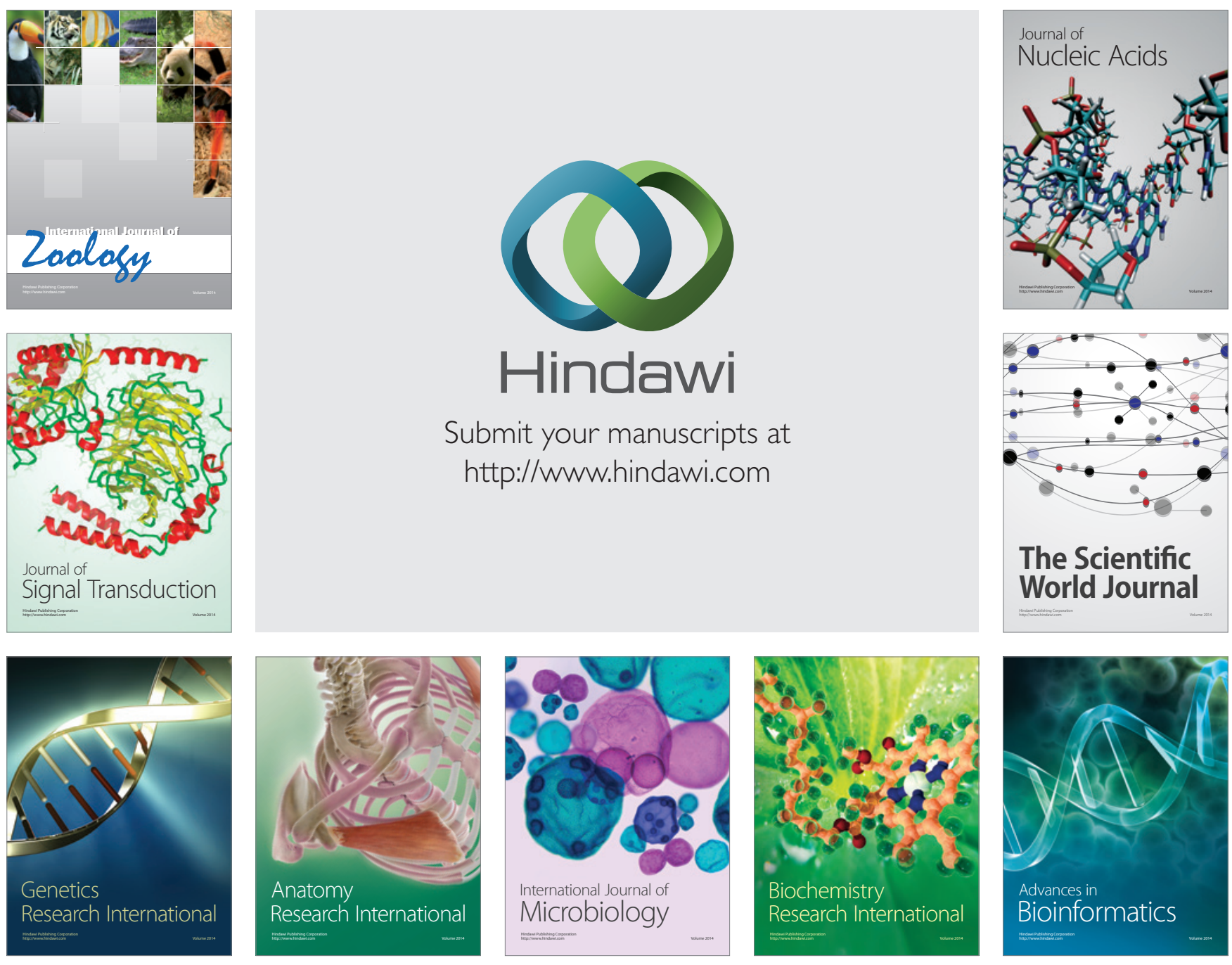

The Scientific World Journal
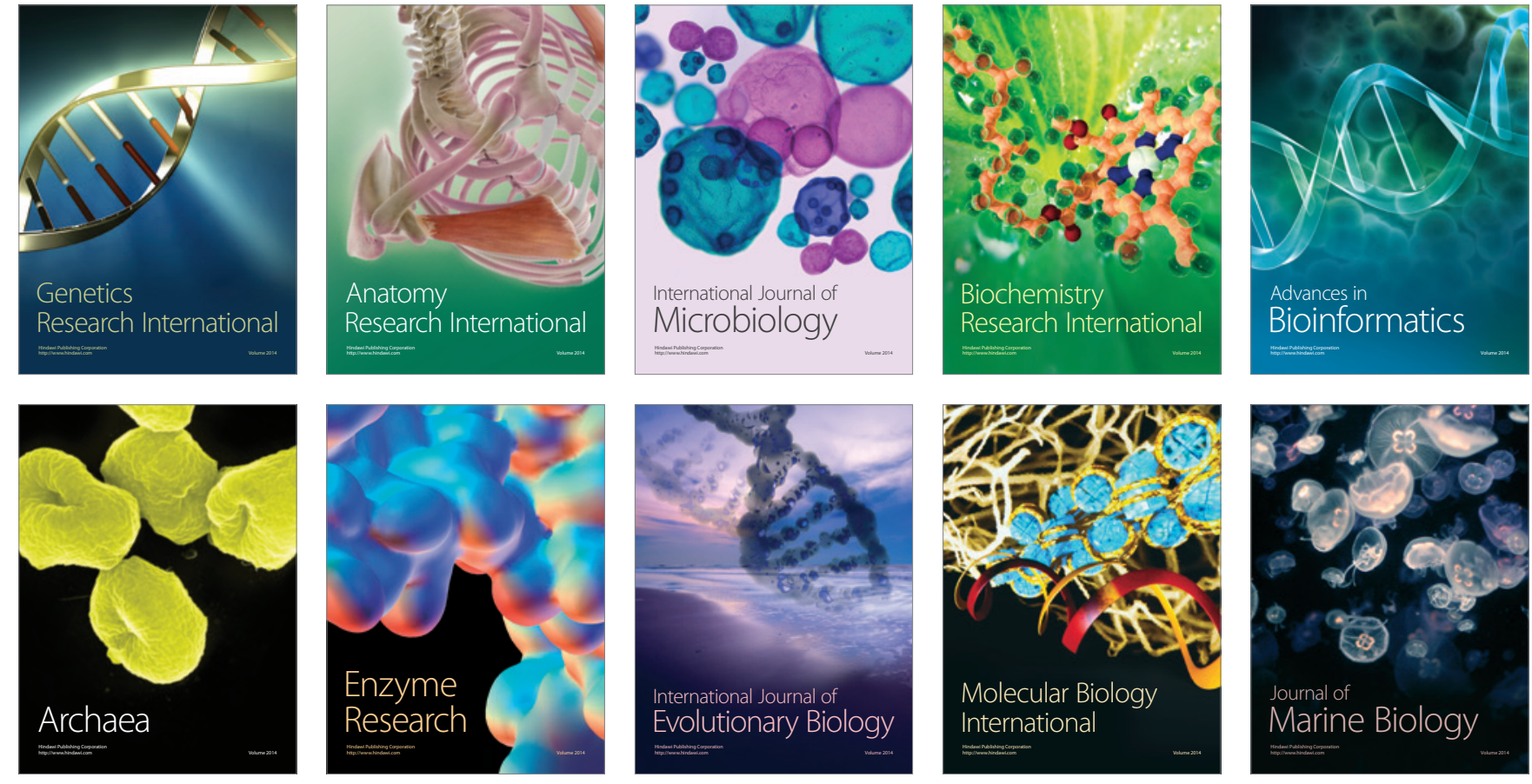